\title{
The Study of Gawai Antu Disappearance and Its Sustainability Among Youths In Sarawak
}

\author{
John Abigail $\mathrm{T}^{1}$, Sulaiman Nur Faizzah ${ }^{1}$, and Aziz Adrianna ${ }^{1}$ \\ Faculty of Hotel and Tourism Management \\ Universiti Teknologi MARA (UiTM) Sabah \\ Kampus Kota Kinabalu, Beg Berkunci 71 \\ 88997 Kota Kinabalu, Sabah \\ abigailtunga.john@gmail.com
}

\begin{abstract}
Gawai Antu is a festival celebrated by the Iban in Sarawak to commemorate the dead soul who has passed away since the last Gawai Antu feast. However, contrary to the main harvest festival, Gawai Dayak, this celebration is less likely to be celebrated among the Ibans due to various reasons. This research aims to investigate the disappearance of Gawai Antu and determine its sustainability. This research could significantly contribute to the Iban community and to the state government of Sarawak where it could help in building greater understanding on the factors affecting the disappearance of Gawai Antu and suggestions on how to revive and sustain the festival. The study is focused on youths in Sarawak with the sample of the study was 88 youths in Kuching. This research is based on data obtained from a survey questionnaire and was analysed by using descriptive analysis. The data were gathered using Stratified Random Sampling and Convenience Sampling Technique. The research suggested that the extinction of Gawai Antu celebration is linked to modernization, religious barrier with cost and time constraints. The results also suggested that the three dimensions of sustainability of Gawai Antu are important to curb the disappearance of this festival namely, collaboration via partnerships, preservation and protection of the festival, and keeping the quality and authenticity of the festival. As this celebration is one of its kind, it would be recommended that production of more credible sources, creating practical exhibitions, and cooperation between relevant agencies would help in keeping the festival alive.
\end{abstract}

Keywords: Cultural Tourism, Festival, Gawai Antu, Sustainability, Youths in Sarawak

\section{Introduction}

Sarawak is located at the northwest of Borneo Island and is the $13^{\text {th }}$ state of Malaysia. Habitat to 54 species of Hornbills in the world, Sarawak is known as "Land of the Hornbills" and the Rhinoceros Hornbill was made the State's Emblem. It is also home to approximately 40 ethnic groups, including Iban, Bidayuh, Melanau, Lun Bawang, Kenyah, Kelabit and so much more. With such diverse ethnicity, Sarawak is the place where cultural beliefs and practices are still relevant even in the $21^{\text {st }}$ century. "Sarawak, where adventure lives" is a promotional slogan used by Sarawak Tourism Board to give a hint of what to expect of this destination. Unique topography along with vast cultural practices is two elements that could be merged and thus producing a "nature, culture and adventure" based tourism product. However, some cultural practices are seen to be disappearing. 
This study is to investigate one of the disappearing practices of the Iban community which is known as Gawai Antu and to determine its sustainability. The research objectives of this study are:

i. To determine the factors that cause Gawai Antu to disappear from the perspective of youths in Sarawak; and

ii. To determine the sustainability of the festival in the future.

\section{Theoretical Framework}

This study is adopting a study framework from the previous research by Lussetyowati (2015) entitled, Preservation and Conservation Through Cultural Heritage Tourism, Case Study of Musi Riverside. Here, Lussetyowati is proposing that to sustain the Musi Riverside Palembang, one must focus on quality and authenticity; practise preservation and protection; finding the fit, and collaboration via partnerships. In the context of Gawai Antu, it would be enough to adopt all three points except for finding the fit. Focusing on quality and authenticity is when the originality of the festival is kept intact, and the quality is assured by minimizing any modern rendition of the festival. Next is to practise preservation and protection, where the festival should be protected and preserved as the identity of the Iban community by having the festival to be celebrated frequently with the correct order. Collaboration can be done via partnership with other business or local community as there are lots of things can be achieved by working together with different parties. The outcome from this collaboration may develop local support to cater the tourism demand. Apart from that, the involvement of the local community, political leaders, hotel operators and other local support are crucial in managing and marketing the product. Festival is an authentic product owned by a specific indigenous group that needs a special attention from the local or organization to sustain it, especially for future generation. Lussetyowati (2015) highlights the importance of regional partnership and its relationship with cultural heritage tourism is to facilitate the resources such as money for marketing campaigns as well expertise or facilities preservation, tourism and the arts.

\section{Methodology}

This study is focusing on youths in Sarawak and the place of distribution was done at UiTM Kampus Samarahan, and UiTM Kampus Samarahan 2. This study is using a quantitative method by collecting the data using questionnaire distribution. The questionnaire consists of three sections. In section A, it is to gather the demographic backgrounds of the respondents. Section B measured the factors affecting Gawai Antu to disappear by using the 5-point Likert scale ranging from 1 to 5, whereby 1 is representing "Strongly Disagree" and 5 representing is "Strongly Agree". Section C focused on the sustainability of Gawai Antu and it was divided into three dimensions following the theoretical framework. The sampling method for this study is Stratified Random Sampling which Hopkins (2000) explained, is suitable to be used in obtaining information from subgroups such as genders, races, regions and so on.

Another method is Convenience Sampling Technique as we are distributing our questionnaires through google docs where respondents could open the link given in the through social media platforms such as WhatsApp and Facebook. Awang (2010) mentioned that this sampling technique is to acquire sample conveniently and answering questionnaires online, is very convenient as compared to answering printed questionnaires. A Pilot test was done using 30 samples from Sarawakian students in UiTM Kampus Kota Kinabalu and the reliability coefficient value was 0.72 . Sekaran (2003) highlighted that reliability coefficient 
value which is nearing 1.0 is the best; 0.6 is poor, 0.7 is acceptable, 0.8 and above is good. Hill (1998, as cited in Johnson \& Brooks, 2010) mentioned that 10 to 30 participants are sufficient to run a pilot study. The data was analysed using Statistical Package for Social Science (SPSS). The data used frequencies to get the percentage, standard deviation and mean by using descriptive and correlation to identify the relationship.

\section{Literature Review}

Cultural Tourism is one of the most steadily blooming branches of the tourism industry worldwide (Csapo, 2012). Cultures that are related to tourism is categorized into three distinct categories namely, Art Tourism, Heritage Tourism, and Place-specific Tourism (Ashworth, 1995 as cited in Mousavi, Doratli, Mousavi, and Moradiahari, 2016). Ashworth (1995, as cited in Mousavi et. al., 2016) mentioned that Art Tourism is related to artistic products such as fine arts and museums whilst Heritage Tourism is focusing on historical buildings and events in a destination. Place-specific Tourism, on the other hand, is viewed as a common set of values, attitudes and behaviours. Csapo (2012) listed out the types of Cultural Tourism and one of the products under this umbrella is Event and Festival Tourism. UNESCO (2003, as cited in Rodzi, Zaki, and Subli, 2013) defined cultural heritage as an intangible set of practices, portrayal, articulation, learning, aptitudes - and in addition the instruments, articles, antiques and social spaces related therewith - that networks, gatherings and, at times, people perceive as a major aspect of their social legacy. Five major areas are highlighted to signify that cultural heritage is intangible and the third element is "Social practices, rituals and festive events" (UNESCO, 2003, as cited in Rodzi et. al., 2013).

\section{Event and Festival}

Event and festival are another dimension within the cultural tourism spectrum that helps to embellish this branch of the industry. Liu (2012) stated that event tourism is a form of cultural tourism which provides a national and international exposure of the destination in terms of product differentiation and variety of recreation experiences for both local and regional market. According to Getz (2007), in general, cultural celebrations such as festivals, carnivals and religious events are being linked to cultural tourism. Culture is a prerequisite for the development of the public sphere of one tribe where it gives a tribe a sense of identity, attachment to a place and social participation. Falassi (1995, as cited in Celik and Cetinkava, 2013) mentioned that the definitions of festivals are divided into three. Firstly, a celebration based on holy and cultural traditions and customs; secondly, celebrations of important people or an event and cultivation of an important crop; and lastly, public fairs and feasts. In relation to this, Kwon (2016) indicates that the designation of ritual practice as Intangible Cultural Heritage by the Pamson Village, South Korea in 1999 took place because the villagers foresaw their ritual practice as a living tradition which coexisting with the history of their village. The similarity of the values held by the Gawai Antu festival with Pamson Village in South Korea put this ritual as part of the intangible cultural heritage.

\section{Gawai Dayak vs. Gawai Antu}

Gawai is a celebration that has been celebrated by the Dayaks; inclusive of Iban and Bidayuh, of the Borneo Island, Malaysia (Ohsey, 2014). Gawai, as defined by Howell and Bailey (n.d., as cited in Richards, 1962) brings the meaning of feasts. Feast is usually associated with a large meal, often has the elements of celebration. Gawai Antu is usually confused with the Gawai Dayak. Gawai Dayak is the result of politicised and modernised Gawai as reported by 
Munan (2018) as he said that Gawai Dayak is an alternative fought by the Dayak leaders during the colonial era to put a halt to the holding of various gawais, with a different purpose at different villages for a very long time. Gawai Antu, on the other hand, is a celebration which ends all mourning for the dead. This feast is the biggest celebration for the Ibans celebrated in honour of those that have passed since the previous Gawai Antu was held (Grijih, 2009). Sandin (1980) explained Gawai Antu as the greatest and the merriest festival that is held in honour of the spirits of the dead and should be celebrated at least once in fifteen years. There have been writings on the disappearing of Gawai Antu. Among the reasons for its disappearance are: costly and time-consuming (Ishak, 2014); religious barriers (Yi, 2017), and modernization (Wong, 2015).

Gawai Antu needs thorough specifications during and before the festival, therefore, people of the Iban community dare not to celebrate it without the knowledge and supervision of the wise. Gawai Antu costs a lot and it needs a very organized planning that some families are feeling the pinch of it (Ishak, 2014). In an interview with Borneo Post, Tuai Rumah Chendang Ambau said that, to complete a Gawai Antu celebration, important rituals such as Beburong ceremony needs to be executed followed by sacrifices of chickens and pigs, cockfighting and also offering of rice to the departed souls are among the reasons why the celebration is very expensive to prepare (Ishak, 2014). Religious belief is also one of the reasons why Gawai Antu is slowly disappearing (Yi, 2017). Gawai Antu carries out Miring as it is an offering given to the deceased and gods of Hades. In a more modern and current scenario, miring is not practical as it is said to go against Christianity. As most Ibans are Christians, they would have to abandon this cultural practice. Ruekeith (2011) said that Miring ceremony now is replaced with church services. It shows that the authenticity of the festival is no longer sustained. Even the slaughtering of the animal, mainly boar, is done by the elderly as the younger generation are disgusted and could not deal with the brutality and this tradition is slowly dying (Wong, 2015). Due to modernization, Gawai Antu or any Gawai, in general, are seen to be a festival where everyone looks forward to due to the merriness, with the unending flow of booze and dancing all night long, the younger generation fails to see the true meaning of Gawai (Ohsey, 2014). Tangga Merakai, told The Rakyat Post that he is the only one who could still practise Miring and Bebiau ceremony in his village in Lubok Antu because none of his children is willing to learn this culture like how he learned it from his grandfather; his children and grandchildren would rather stay inside than to participate in any cultural rituals (Wong, 2015).

\section{Findings and Discussion}

A total of 88 respondents took part in this study which came from different genders. The result showed that $69.32 \%$ of them are female whilst the remaining $30.68 \%$ are male. Most of the respondents are at the age of 21-23 years old with a total of 40 students. Not to mention, there were at least 33 respondents which are at the age of 18-20 years old followed by 15 respondents at the age of 24 years and above. Therefore, it could be summed up that the highest numbers of respondents were from the age of 21-23 years old.

Section B of the questionnaire is about the factors affecting Gawai Antu disappearance. As this section uses a Likert scale, therefore it was analysed using a frequency table. Any item with mean responses that are higher than 3.5 will be considered as an important factor that contributed to the disappearance of Gawai Antu. The study found that most of the respondents believed that the celebration is against their belief or religion as it has a 3.24 mean score. The respondents also agreed on the limited knowledge that they possessed 
$\left({ }^{-} \mathrm{x}=3.55\right)$ pertaining to Gawai Antu celebration. Apart from that, the result also shows that their family did not give enough exposure $\left({ }^{-} \mathrm{x}=3.41\right)$ about the celebration. It was an established fact that respondents agreed upon the fact that Gawai Antu is still relevant to celebrated today $\left({ }^{-} \mathrm{x}=3.67\right)$ and claimed that this celebration is seen to be as important as Gawai Dayak $\left({ }^{-} \mathrm{x}=3.45\right)$. In addition, this celebration appeared to be costly and timeconsuming $\left({ }^{-} \mathrm{x}=3.47\right)$ to some respondents.

The first objective of this study is to determine the factors that cause Gawai Antu to slide towards disappearance from the perspective of Sarawakian youths. Under this objective, we managed to identify three factors namely, modernization, religious barrier and costly and time-consuming. Based on the analysed data, with a mean value of 3.67, most people agree that Gawai Antu is still relevant to be practised today. From this result, most people agree that Gawai Antu is still relevant in today's setting. The second highest mean value is 3.55 which is for the statement on "I have little knowledge about Gawai Antu celebration". From these two analyses, it is related because most of the people admitted that they have very little knowledge about the celebration. However, they are still aware of the cultural values it promotes because they still think it is relevant to be celebrated now. To say that the celebration is relevant or otherwise would be one's perception. However, with very little knowledge about the celebration, one can be ignorance about the festival. Therefore, modernization does cause Gawai Antu to slide towards disappearance. The next mean value of 3.47 is for the item which states Gawai Antu celebration is costly and time-consuming. Based on that mean value, modernization is seen to be significant in causing Gawai Antu to slide towards disappearance as mentioned by Wong (2015), followed by the cost and time as mentioned by Ishak (2014) and finally is the religious barrier as stated by Yi (2017).

Section C of the questionnaire is on the sustainability of Gawai Antu based on the theoretical framework. The first dimension is focusing on collaboration among responsible parties. The result is satisfying as most of the respondents think that this action could help in sustaining the festival. Like section $\mathrm{B}$, the mean value that exceeds 3.5 will be more significant. Most of the respondents think that tourism players play a critical role in turning Gawai Antu as one of the important tourism products in Sarawak. The mean of this item is higher $\left({ }^{-} \mathrm{x}=4.31\right)$ in comparison to other items showing that respondents have agreed that tourism industry players play a critical role in the promotion of Gawai Antu. Apart from that, the help from different parties is seen to be important in sustaining Gawai Antu celebration $(-\mathrm{x}=4.25)$ to inscribe it as a UNESCO World Heritage $\left({ }^{-} \mathrm{x}=4.17\right)$. In addition, respondents also indicated that the collaboration between the local community and state government should be done to preserve Gawai Antu celebration.

For the first dimension, which is collaboration, with the mean value of 4.31 based on the analysed data, all respondents agreed that tourism industry players should promote Gawai Antu as an important product in Sarawak. With the mean value of 4.25, respondents are agreeing to the statement saying that the help from different parties is important to sustain the festival. Different parties are, for example, tourism players working together with the media to promote the festival through any media platforms such as television advertising or documentary movies. A group of respondents also agree that the collaboration between the state government, local community and tourism players is very crucial to make Gawai Antu to be inscribed as one of the UNESCO World Heritage Cultural Events with the mean value of 4.17. Collaboration between responsible bodies with the local community is important as it helps to increase tourists' visits and for economic benefits to the local communities. Musa (2017) reported that the previous Minister of Tourism, Arts, and Culture (Malaysia), Datuk Seri Mohamed Nazri Abdul Aziz has listed three cultural events to be inscribed under 
UNESCO World Heritage namely, the Wangkang Ceremony, Dondang Sayang performance and Pantun. This could also be an advantage to propose Gawai Antu as one of the festivals to be inscribed under UNESCO World Heritage for its uniqueness as there is no other known similar ritual celebration worldwide as to how it is being celebrated.

The second dimension of the theoretical framework which is preservation and protection is to see the comprehension of the respondents on the awareness of preserving and protecting this festival which is sliding towards disappearance. The mean value exceeding 3.5 is significant. Most of the respondents agree that it is the responsibility of the local community in making sure the tradition of Gawai Antu celebration $(-\mathrm{x}=4.43)$ alive appeared to be the most important area for the respondents. The respondents also indicated that the celebration of Gawai Antu is the identity of the Iban community $\left({ }^{-} \mathrm{x}=4.34\right)$. Most importantly, the respondents are aware that this festival is sliding towards disappearance $\left({ }^{-} \mathrm{x}=\right.$ 4.30) and the importance of preserving $\left({ }^{-} \mathrm{x}=4.26\right)$ it for the Iban community.

For the second dimension, most respondents agree that in preserving the celebration, the local communities play a major role in preserving the celebration. This automatically becomes the responsibility of the Iban people because this celebration was passed down from their ancestors to them and no one knows about this celebration better than the community itself. The mean value of this value is 4.43. Respondents also said agree that Gawai Antu is the identity of the Iban community with a mean value of 4.34. In this section also, they are aware that Gawai Antu is sliding towards disappearance where it means value reads as 4.30. Here, we could conclude that preservation and protection are important where the preservation should be done by the local community as Swarbrooke (1999) also highlighted that local communities play the most important role in sustaining their "property". In this case, "property" is referred to as the celebration of Gawai Antu.

The third dimension of the theoretical framework is focusing on quality and authenticity. The mean value exceeding 3.5 is significant. In this dimension, all the mean value for each item is below the average score. As highlighted in the result, respondents' family and longhouse did not celebrate Gawai Antu frequently $\left({ }^{-} \mathrm{x}=2.50\right)$. The respondents seemed to be unclear with the celebration $\left({ }^{-} \mathrm{x}=3.02\right)$, and they are not exposed to the information related to Gawai Antu $\left({ }^{-} \mathrm{x}=3.05\right)$. Not to mention, most of the family seldom celebrate this festival according to the original ritual without any modern rendition. Based on the pattern of the mean value, this third dimension is the least given attention to. From this dimension, we could conclude that most respondents are not very familiar with the celebration which refers to the factors causing the celebration to slide towards disappearance which is modernization. For this dimension also, Lussetyowati (2015) explained that focusing on quality and authenticity is to have these two elements to be incorporated together alongside making a product a tourism product. As for the context of the study, the originality of the celebration should be maintained as to how it was celebrated by their ancestors. Most respondents are not exposed to the celebration because their longhouses do not practise the celebration anymore. Therefore, keeping the quality and authenticity should be practised because most people are not exposed to the celebration.

\section{Limitations}

One of the challenges in would be lacking of references which are similar to the study. It is also difficult to find literatures that specifically explained the administrative and conservation part of this tradition. Apart from that, the research conducted may not be considered as comprehensive as only limited respondents participated in the study. 


\section{Recommendations}

We would like to recommend more credible sources relating to Gawai Antu celebration to be produced. As we are living in a vast and modern world, we should be able to utilize it for record keeping and so on. Not only should the audio video of the celebration be taken but also audio recordings of the poem invocations of the Lemambang to let the younger generation understand and practice the words so that they can memorise and recite the rites correctly. Another recommendation is to have cloned Gawai Antu festival to be celebrated in Sarawak Cultural Village. For example, the performance of Sininggazanak being staged in J Borneo Native Village in Penampang, Sabah where they do a musical on the story of the Sininggazanak.

Finally, we recommend that government bodies and tourism players, work together in having this celebration to be listed under UNESCO Intangible Cultural Heritage Lists in Need of Urgent Safeguarding. This is because, the value of this celebration is very precious and now that it is disappearing; people should be alarmed about this matter. Therefore, this requires collaboration and hard work from all parties to ensure listing from UNESCO and subsequently the preservation of this celebration. Taking the example of Biyelgee (a Mongolian folk dance) that has been inscribed in the UNESCO list in the year 2009, Gawai Antu could also be done the same. It is our duty to guarantee the continuity and sustainability of our tradition as the heir of our forefather. The modern world may influence our way of thinking, but it should not be an excuse to stop us from protecting and preserving the way of life our ancestors once practised.

\section{Conclusion}

This study is a success as we were able to prove that modernisation, cost and religious beliefs are among the reasons of Gawai Antu to slide towards disappearance. However, these factors could be studied further in the future to see the significance of these factors. The results have shown that most of the youngsters are not familiar with the celebration of Gawai Antu. Therefore, this leads to another factor which is, they are not aware if the celebration is costly or time-consuming and if the ceremony is against the religious beliefs or otherwise. But in the sustainability dimension, most of them want Gawai Antu to be preserved and they also agree that this celebration is made as a tourism product like Pesta Kaul celebrated by the Melanau or the Hungry Ghost Festival celebrated by the Chinese.

\section{References}

Awang, Z.H. (2010). Research methodology for business and social sciences. Shah Alam, Malaysia: University Publication Centre (UPENA).

Çelik, S. \& Çetinkay, M.Y. (2013). Festivals in event tourism: the case of international Izmir art festival. International Journal of Contemporary Economics and Administrative Sciences, $1-21$.

Csapó, J. (2012). The role and importance of cultural tourism in the modern tourism industry. In D.M. Kasimogl, The role and importance of cultural tourism in the modern tourism industry, strategies for the tourism industry - Micro and macro perspectives (pp. 202232). Rijeka, Croatia: InTech. 
Getz, D. (2007). Event tourism: Definition, evolution and research. Progress in Tourism Management, 403-428.

Grijih, H. (2009). Gawai Antu. Retrieved from https://tusunterabai.wordpress.com/adat-mainasal-leka-main/gawai-antu/

Hopkins, W.G. (2000). Quantitative research design. 2-3. Auckland, New Zealand.

Ishak, O. (2004). Families at Rh. Cendang holds Gawai Antu. The Borneo Post. Retrieved from http://www.theborneopost.com/2014/06/06/families-at-rh-chendang-hold- gawaiantu/

Johnson, G.A. \& Brooks, G.P. (2010). Initial scale development: sample size for pilot studies. Educational and Psychological Measurement, 395-396.

Kwon, H. (2016). Villagers' agency in the intangible cultural heritage designation of a Korean village ritual. International Journal of Heritage Studies, 1-15.

Liu, Y.-D. (2012). Cultural events and cultural tourism development: lessons from the European capitals of culture. European Planning Studies, 498-514.

Lussetyowati, T. (2015). Preservation and conservation through cultural heritage tourism. Case study: Musi riverside Palembang. Procedia Social and Behavioral Sciences, 3-6.

Mousavi, S.S., Doratli, N., Mousavi, S.N., \& Moradiahari, F. (2016). Defining cultural tourism. International Conference on Civil, Architecture, and Sustainable Development, (pp. 70-75). London.

Munan, S. (2018). Why a new festival was created. The Borneo Post. Retrieved from http://www.theborneopost.com/2018/06/03/why-a-new-festival-was-created/

Musa, N. (2017). Dondang Sayang, pantun ke UNESCO. The Sinar Online. Retrieved from http://www.sinarharian.com.my/ultras/liga-malaysia/dondang-sayang-pantun-keunesco-1.647399

Ohsey, C. (2014) Kepupusan hari gawai?. Retrieved from http://www.projekdialog.com/featured/kepupusan-hari-gawai/

Richards, A. (1962). The sea dayaks and other races of Sarawak. Kuching, Malaysia: Borneo Literature Bureau.

Rodzi, N.I., Zaki, S.A., \& Subli, S.M. (2013). Between tourism and intangible cultural heritage. Procedia - Social and Behavioral Sciences, 411-420.

Ruekeith, G.O. (2011). Dayak community welcomes Gawai today. The Borneo Post. Retrieved from http://www.theborneopost.com/2011/06/01/dayak-communitywelcomes-gawai-today/

Sandin, B. (1980). Iban adat and augury. Kuala Lumpur, Malaysia: Penerbit Universiti Sains Malaysia.

Sekaran, U. (2013). Research Methods For Business. New York, NY: John Wiley \& Sons, Inc.

Swarbrooke, J. (1999). Sustainable tourism management. Massachusetts, MA: CABI Publishing.

Wong, D. (2015). The dying traditions of "Miring" and "Berbiau". The Rakyat Post. Retrieved from http://www.therakyatpost.com/news/2015/06/04/the-dying-traditionsof-miring-and-berbiau-video/

Yi, C. (2017). Berantu: A special memorial for the dearly departed. The Borneo Post. Retrieved from http://www.theborneopost.com/2017/06/25/berantu-special-memorialfor-the-dearly-departed/ 